\title{
AMPD1 gene mutations are associated with obesity and diabetes in Polish patients with cardiovascular diseases
}

\author{
Krzysztof Safranow • Janina Suchy • Katarzyna Jakubowska • Maria Olszewska • \\ Agnieszka Bińczak-Kuleta • Grzegorz Kurzawski • Ryszard Rzeuski • \\ Edyta Czyżycka • Beata Loniewska • Zdzisława Kornacewicz-Jach • \\ Andrzej Ciechanowicz $\cdot$ Dariusz Chlubek
}

Received: 1 February 2010 /Revised: 2 July 2010 / Accepted: 27 July 2010 /Published online: 25 November 2010

(C) The Author(s) 2010. This article is published with open access at Springerlink.com

\begin{abstract}
Previous studies showed an association of the common functional polymorphism (C34T, Gln12Stop) in the adenosine monophosphate deaminase-1 (AMPD1) gene with survival in heart failure (HF) and/or coronary artery disease (CAD). The aim of the study was to search for other mutations in selected regions of the AMPD1 gene in Polish $\mathrm{CAD}$ and HF patients, and to analyze their associations with obesity and diabetes. Exons 2, 3, 5, and 7 of AMPD1 were scanned for mutations in 97 patients with $\mathrm{CAD}$ without $\mathrm{HF}(\mathrm{CAD}+\mathrm{HF}-), 104$ patients with $\mathrm{HF}(\mathrm{HF}+)$, and 200 newborns from North-Western Poland using denaturing high-performance liquid chromatography (DHPLC), polymerase chain reaction-restriction fragment length polymorphism (PCRRFLP), and direct sequencing. Frequencies of AMPD1 C34T
\end{abstract}

K. Safranow $(\bowtie) \cdot$ K. Jakubowska $\cdot$ M. Olszewska $\cdot$ D. Chlubek Department of Biochemistry and Medical Chemistry,

Pomeranian Medical University,

Powstańców Wielkopolskich 72,

70-111, Szczecin, Poland

e-mail: chrissaf@mp.pl

J. Suchy $\cdot$ G. Kurzawski

Department of Genetics and Pathology,

Pomeranian Medical University,

Szczecin, Poland

\author{
A. Bińczak-Kuleta $\cdot$ A. Ciechanowicz \\ Department of Laboratory Diagnostics and Molecular Medicine, \\ Pomeranian Medical University, \\ Szczecin, Poland \\ R. Rzeuski $\cdot$ E. Czyżycka $\cdot$ Z. Kornacewicz-Jach \\ Department of Cardiology, Pomeranian Medical University, \\ Szczecin, Poland \\ B. Łoniewska \\ Department of Neonatology, Pomeranian Medical University, \\ Szczecin, Poland
}

mutation, as well as novel A99G, G512A, IVS4-6delT, and C784T sequence alterations, were similar in the three groups, but $860 \mathrm{~T}$ mutated allele was less frequent in the combined $\mathrm{CAD}+\mathrm{HF}-$ and $\mathrm{HF}+$ groups than in the controls $(1.7 \%$ vs. $4.3 \%, p=0.040)$. Heterozygous $34 \mathrm{CT}$ genotype was associated with lower (odds ratio $[\mathrm{OR}]=0.32,95 \%$ confidence interval $[\mathrm{CI}]=0.13-0.81)$ and $860 \mathrm{AT}$ with higher $(\mathrm{OR}=13.7,95 \% \mathrm{CI}=$ 1.6-118) prevalence of diabetes or hyperglycemia in relation to wild-type homozygotes. Abdominal obesity was more frequent in $860 \mathrm{AT}$ patients than in wild-type homozygotes and $34 \mathrm{CT}$ heterozygotes ( $86 \%$ vs. $40 \%$ vs. $29 \%, p<0.05$ ). Nine genes containing polymorphisms linked with AMPD1 C34T mutation were found in the HapMap database. AMPDI C34T nonsense mutation is associated with reduced prevalence of diabetes and obesity in patients with CAD or HF, but A860T substitution seems to exert opposite metabolic effects and should always be accounted for in the studies of the AMPD1 genotype.

Keywords AMP deaminase-1 C Coronary artery disease . Denaturing high-performance liquid chromatography. Diabetes $\cdot$ Heart failure $\cdot$ Human genetics $\cdot$ Obesity

\section{Introduction}

Previous studies showed an association of the common C34T polymorphism in the AMPD1 gene with survival in patients with heart failure (HF) and coronary artery disease (CAD). Adenosine monophosphate deaminase (AMPD, EC 3.5.4.6) catalyzes the deamination of adenosine monophosphate (AMP) to inosine monophosphate (IMP). The AMPD1 gene located at 1p13 encodes isoenzyme which expresses the highest activity in skeletal muscles (Morisaki et al. 1990). The AMPD2 and AMPD3 genes encode liver and erythrocyte isoenzyme, respectively. The 
AMPD1 gene sequence consists of 22,455 base pairs (bp) including 16 exons (RefSeq NG_008012) (Sabina et al. 1990). 2,341-bp mRNA (RefSeq NM_000036.1) encodes the 747-aa protein (RefSeq NP_000027.1, Swiss-Prot P23109).

The common C34T (Gln12Stop, rs17602729) polymorphism in the $A M P D 1$ gene results in a premature stop codon in exon 2, and, thus, in an inactive enzyme. T34 allele frequency in Europeans amounts to $10-15 \%$ (Morisaki et al. 1992; Norman et al. 1998). About 2\% of Europeans are 34TT homozygotes (Norman et al. 1998). For many years, the lack of AMPD activity in muscles was considered as the cause of myopathy (MIM 102770) (Sabina et al. 1980). However, subsequent studies showed that most subjects with 34TT genotype, in spite of no detectable activity of AMPD in muscles, did not present any myopathy symptoms (Gross 1997).

C34T mutation is linked with C143T (rs61752479, Pro48Leu) substitution in exon 3, which does not affect enzyme function in vitro (Morisaki et al. 1992), but it is difficult to estimate its influence in vivo due to the linkage disequilibrium with $\mathrm{C} 34 \mathrm{~T}$. Less frequent $A M P D 1$ mutations were found in exons 5 (G468T, Gln156His) (Gross et al. 2002; Fischer et al. 2005) and 7 (A860T, Lys287Ile, rs34526199) (Toyama et al. 2004). Additionally, mutations in exons 3 (A44G, Asp15Gly) (Gross et al. 2002), 8 (G930T, Met310Ile) (Toyama et al. 2004), 9 (C1162T, Arg388Trp), and 10 (G1274A, Arg425His) (Morisaki et al. 2000), as well as splice site deletion in intron 2 IVS2-(4-7) delCTTT (Isackson et al. 2005), resulting in an enzyme with very low or no activity, were described in single patients or families.

Some reports suggested that T34 allele was associated with improved outcome in patients with HF (Loh et al. 1999; Gastmann et al. 2004; Yazaki et al. 2004) and improved cardiovascular survival in patients with $\mathrm{CAD}$ (Anderson et al. 2000), while other reports did not confirm such associations (Andreassi et al. 2005; Kolek et al. 2005; de Groote et al. 2006). The results of the Collins et al. study (2006) suggested that the T34 allele was associated with poorer outcome in patients with a history of myocardial infarction. No previous reports analyzed the associations of other polymorphisms in the AMPDI gene with the phenotype of cardiovascular diseases.

Metabolic syndrome including obesity and diabetes is a major risk factor for CAD. The association of AMPD1 C34T mutation with components of the metabolic syndrome in Polish patients with cardiovascular diseases was previously analyzed (Safranow et al. 2009). The aim of the current study was to search for other mutations in selected regions of the AMPD1 gene in Polish patients with $\mathrm{CAD}$ or HF, as well as in newborns treated as the genetic control group, and to analyze their associations with obesity and diabetes. We also investigated the linkage disequilibrium between the $A M P D 1$ mutations and sequence alterations of neighboring genes.

\section{Materials and methods}

The study groups comprised of patients treated at the Department of Cardiology, Pomeranian Medical University in Szczecin, in the years 2004-2006. The patients were all of Polish descent and most of them were from Szczecin and its nearby neighborhood (North-Western Poland). The patients included in this study were clinically stable, with optimal pharmacological treatment and no acute coronary syndromes, HF exacerbations, or revascularization procedures within the last month. This study was approved by the institutional Ethics Committee. Informed consent was obtained from each patient.

CAD diagnosis was based on coronary angiography. The criteria for HF diagnosis included the presence of clinical symptoms, HF features in echocardiography, and elevated plasma B-type natriuretic peptide (BNP) concentration. Patients with hemodynamically significant congenital or acquired valve diseases were excluded.

The CAD + HF- group comprised 97 patients aged 58.2 \pm 8.6 years $(77 \%$ men) with CAD (duration of symptoms $6.2 \pm$ 5.9 years, $67 \%$ with past myocardial infarct) but without $\mathrm{HF}$. The HF+ group comprised 104 patients aged $58.9 \pm 9.6$ years (79\% men) with HF (duration of symptoms $4.7 \pm 5.0$ years, New York Heart Association [NYHA] class 2.1 \pm 0.8 ). In 70 patients $(67 \%)$, the etiology of HF was ischemic, in $23(22 \%)$ it was non-ischemic, and in 11 patients (11\%) it was complex.

The control group consisted of 200 consecutive newborns (96 males) of Polish origin born at the Department of Neonatology, Pomeranian Medical University in Szczecin, in the years 2004-2005. DNA was isolated from their umbilical cord blood.

\section{Genotyping}

Genomic DNA was extracted from $0.15 \mathrm{~mL}$ of $\mathrm{K}_{3}$ EDTAanticoagulated blood with a QIAamp DNA Mini Kit (QIAGEN). The previously described polymerase chain reaction-restriction fragment length polymorphism (PCRRFLP) method with Tai I restriction enzyme was used to detect $\mathrm{C} 34 \mathrm{~T}$ substitution in exon 2 of the AMPD1 gene (Safranow et al. 2009).

For denaturing high-performance liquid chromatography (DHPLC) analysis and for direct sequencing of exons 2, 3, 5 , and 7, DNA was amplified by PCR using exon-flanking primers (Table 1). The reaction was carried out in a total volume of $25 \mu \mathrm{L}$ containing: $40 \mathrm{ng}$ of template DNA, 7.5 pmol of each primer (HPSF, MWG-Biotech AG), PCR buffer $(10 \mathrm{mM}$ Tris- $\mathrm{HCl}, 50 \mathrm{mM} \mathrm{KCl}, \mathrm{pH}=8.9), 2 \mathrm{mM}$ 
Table 1 Primer sequences and denaturing high-performance liquid chromatography (DHPLC) temperature for the analysis of the AMPD1 gene fragments

\begin{tabular}{|c|c|c|c|}
\hline AMPDI amplicon & Sense and antisense primer & Product length (bp) & Optimal temperature of DHPLC separation $\left({ }^{\circ} \mathrm{C}\right)$ \\
\hline Exon 2 & 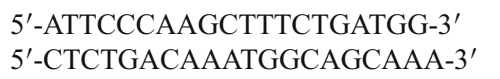 & 210 & 57 \\
\hline Exon 3 & $\begin{array}{l}\text { 5'-AGGGGCTTGAACACTAATATG-3' } \\
\text { 5'-GGCAGATACCCCTCCTTAG-3' }\end{array}$ & 274 & 61 \\
\hline Exon 5 & $\begin{array}{l}\text { 5'-TTTCGTGGGATTGACTCTGA-3' } \\
\text { 5'-GGGGCCAAAGATGATTATGA-3' }\end{array}$ & 341 & 59.5 \\
\hline Exon 7 & $\begin{array}{l}\text { 5'-GAATGCCTGAAACTTTTTGGA-3' } \\
5^{\prime} \text {-GAATTGTTTTTGCCCAGGAA-3' }\end{array}$ & 222 & 61 \\
\hline
\end{tabular}

$\mathrm{MgCl}_{2}, 5 \mathrm{nmol}$ of each dNTP, and $0.3 \mathrm{U}$ of $\mathrm{Taq}$ polymerase (POLGEN). To minimize artifacts associated with replication errors of the exon 5 sequence, which contains a tract of $12 \mathrm{~T}$ nucleotides, high-fidelity Optimase (Transgenomic) polymerase with included buffer and $2.5 \mathrm{mM} \mathrm{MgSO}_{4}$ was used for this amplicon. The amplification was performed using the GeneAmp PCR System 9700 (Applied Biosystems) with initial denaturation at $94^{\circ} \mathrm{C}$ for $5 \mathrm{~min}$ and then 35 cycles as follows: denaturation at $94^{\circ} \mathrm{C}(30 \mathrm{~s})$, annealing at $58^{\circ} \mathrm{C}$ for the first five cycles and $56^{\circ} \mathrm{C}$ for the subsequent 30 cycles (40 s), and extension at $72^{\circ} \mathrm{C}(45 \mathrm{~s})$. The final $72^{\circ} \mathrm{C}$ incubation was extended by $5 \mathrm{~min}$. The quality of PCR products was controlled by electrophoresis on $2 \%$ agarose gel stained with ethidium bromide, photographed in UV light.

DHPLC analyses were performed with the HewlettPackard 1050/1100 system and a Helix DNA column (CP28353, Varian) (Kurzawski et al. 2002). PCR products were denatured $\left(95^{\circ} \mathrm{C}, 5 \mathrm{~min}\right)$ and reannealed by slowly decreasing the temperature $\left(1^{\circ} \mathrm{C} / \mathrm{min}\right)$ to allow the formation of heteroduplexes. Then, a $5-10-\mu \mathrm{L}$ sample was injected into the column. The optimal temperature for the analysis of heteroduplexes was initially calculated with the DHPLC Melt Program (http://insertion.stanford.edu/melt. html) (Jones et al. 1999) and subsequently adjusted based on experiments to achieve optimal separation of the homoand heteroduplexes for each amplicon (Table 1).

Samples with DHPLC profiles different from wild-type homozygote were directly sequenced in the forward and reverse directions with the ABI PRISM Dye Terminator Cycle Sequencing Ready Reaction (Applied Biosystems) according to the manufacturer's protocols. Sequences were read with the DNA 377 or 3130 analyzer (Applied Biosystems).

\section{Bioinformatics}

Protein and DNA sequences of the AMPD1 gene in human and 27 other vertebrates were compared using the University of California Santa Cruz (UCSC) Genome Browser (http:// genome.ucsc.edu/). We analyzed the genomes of Homo sapiens (NCBI sequence version 36.1), 19 mammals (Pan troglodytes, Macaca mulatta, Otolemur garnettii, Tupaia belangeri, Mus musculus, Rattus norvegicus, Cavia porcellus, Oryctolagus cuniculus, Sorex araneus, Erinaceus europaeus, Canis familiaris, Felis catus, Bos taurus, Equus caballus, Dasypus novemcinctus, Loxodonta africana, Echinops telfairi, Monodelphis domestica, Ornithorhynchus anatinus), lizard (Anolis carolinensis), chicken (Gallus gallus), frog (Xenopus tropicalis), and five fish species (Danio rerio, Tetraodon nigroviridis, Takifugu rubripes, Gasterosteus aculeatus, Oryzias latipes). Analyses of some loci were limited to a lower number of species when the sequence data were not available.

The BLASTP 2.2.18 program (Altschul et al. 1997) was used to compare human amino acid sequences with invertebrates and other species. Exonic splicing enhancer (ESE) and exonic splicing silencer (ESS) sequences were searched with the ESEfinder (Cartegni et al. 2003) and FAS-ESS (Wang et al. 2004) programs. Linkage disequilibrium between AMPD1 C34T mutation and polymorphisms of other genes located in its vicinity were analyzed using the HapMap database (version 23a) (International HapMap Consortium 2007).

\section{Statistical analysis}

Genotype and allele frequencies as well as other qualitative variables were analyzed with Fisher's exact test (two-sided) implemented in the SISA Tables program (Quantitative Skills) (Agresti 1992). The exact test was also applied to assess the conformity of the genotype distribution to the Hardy-Weinberg law (Guo and Thompson 1992). When tables were too large for exact tests, the $\chi^{2}$ test was used. Confidence intervals for allele frequencies were calculated with the exact test (Clopper and Pearson 1934). Quantitative variables were compared between genotype groups with the Mann-Whitney test.

Haplotype and linkage disequilibrium analyses were performed with the HaploView 4.0 program (Barrett et al. 2005). Lewontin's $D^{\prime}$ value, its $95 \%$ confidence interval, $r^{2}$, and LOD score were calculated for each loci pair. 


\section{Results}

Genotype data

No deviation from the Hardy-Weinberg equilibrium ( $p>$ $0.05)$ was observed for the $A M P D 1$ genotypes in the two study groups and in the controls (Table 2). Mutated 860T allele was less frequent in both study groups than in the controls, and the difference between the combined CAD+ $\mathrm{HF}-$ and $\mathrm{HF}+$ group $(n=201)$ and newborns reached statistical significance $(1.7$ vs. $4.3 \%, p=0.040)$. No other significant differences in the AMPDI genotype and allele frequencies were found between the three groups.

Due to linkage disequilibrium, the T allele in locus 34 was almost always accompanied by the $\mathrm{T}$ allele in locus 143, except for two subjects with the 34CC-143CT genotype. There were two subjects with the 34CT143CT genotype and concomitant G512A substitution and one with a 34CT-143CT-860AT combination. All other $512 \mathrm{~A}$ and $860 \mathrm{~T}$ alleles were detected in $34 \mathrm{CC}-143 \mathrm{CC}$ homozygotes.

Three new variants were found and confirmed by direct sequencing. Synonymous substitution A99G (Gly33Gly) in exon 3 was detected in two newborns (99G allele frequency: $0.25 \%, 95 \% \mathrm{CI}: 0.03-0.9 \%$ ). It was added to the dbSNP recently as rs61752480. Deletion IVS4-6delT in intron 4, which results in truncation of the T-tract located just before the start of exon 5 from $12 \mathrm{~T}$ to $11 \mathrm{~T}$, was found in one allele of a newborn (IVS4-6delT allele frequency: 0.12\%, 95\%CI: 0.003-0.7\%). Substitution C784T (Arg262Trp) in exon 7 was detected in one allele of a $\mathrm{CAD}+\mathrm{HF}-$ patient $(784 \mathrm{~T}$ allele frequency: $0.12 \%, 95 \% \mathrm{CI}$ : $0.003-0.7 \%)$.

The haplotypes consisting of seven polymorphic sites, estimated using expectation-maximization algorithm, are shown in Table 3. No significant differences in the AMPD1 haplotype distribution were found between groups. The frequency of the major haplotype was $79.1 \%$ in the combined groups $(n=401)$. The haplotype carrying the $34 \mathrm{~T}$ allele had a frequency of $16.2 \%$ and the remaining haplotypes were at $4.7 \%$.

Obesity and diabetes

Table 4 compares parameters associated with the metabolic syndrome (obesity, history of diabetes, fasting glycemia)

Table 2 Frequency distribution of $A M P D 1$ sequence alterations in patients with coronary artery disease without heart failure (CAD+ HF-, $n=97)$, patients with heart failure $(\mathrm{HF}+, n=104)$, newborn controls $(n=200)$, and all combined groups $(n=401)$

\begin{tabular}{|c|c|c|c|c|c|c|c|}
\hline \multirow{2}{*}{$\frac{\text { Polymorphism/group }}{\mathrm{C} 34 \mathrm{~T}}$} & \multicolumn{3}{|c|}{ Genotype frequency $(\%)$} & \multirow[t]{2}{*}{$p$-value ${ }^{\mathrm{a}}$} & \multirow{2}{*}{$\frac{\text { Minor allele frequency }(95 \% \mathrm{CI})^{\mathrm{b}}(\%)}{\mathrm{T}}$} & \multirow[t]{2}{*}{$p$-value ${ }^{\mathrm{c}}$} & \multirow[t]{2}{*}{ HWE $p$-value } \\
\hline & $\mathrm{CC}$ & $\mathrm{CT}$ & TT & & & & \\
\hline $\mathrm{CAD}+\mathrm{HF}-$ & 70.1 & 23.7 & 6.2 & 0.29 & $18.0(12.9-24.2)$ & 0.70 & 0.076 \\
\hline $\mathrm{HF}+$ & 71.1 & 26.0 & 2.9 & & $15.9(11.2-21.6)$ & & 0.72 \\
\hline Newborns & 70.5 & 28.0 & 1.5 & & $15.5(12.1-19.4)$ & & 0.43 \\
\hline All & 70.6 & 26.4 & 3.0 & & $16.2(13.7-19.0)$ & & 0.58 \\
\hline $\mathrm{C} 143 \mathrm{~T}$ & $\mathrm{CC}$ & $\mathrm{CT}$ & $\mathrm{TT}$ & & $\mathrm{T}$ & & \\
\hline $\mathrm{CAD}+\mathrm{HF}-$ & 69.1 & 24.7 & 6.2 & 0.30 & $18.6(13.4-24.8)$ & 0.67 & 0.088 \\
\hline $\mathrm{HF}+$ & 71.1 & 26.0 & 2.9 & & $15.9(11.2-21.6)$ & & 0.72 \\
\hline Newborns & 70.0 & 28.5 & 1.5 & & $15.7(12.3-19.7)$ & & 0.43 \\
\hline All & 70.1 & 26.9 & 3.0 & & $16.5(14.0-19.2)$ & & 0.72 \\
\hline G512A & GG & GA & $\mathrm{AA}$ & & $\mathrm{A}$ & & \\
\hline $\mathrm{CAD}+\mathrm{HF}-$ & 95.9 & 4.1 & 0 & 0.16 & $2.1(0.6-5.2)$ & 0.16 & 1.0 \\
\hline $\mathrm{HF}+$ & 98.1 & 1.9 & 0 & & $1.0(0.1-3.4)$ & & 1.0 \\
\hline Newborns & 99.0 & 1.0 & 0 & & $0.5(0.1-1.8)$ & & 1.0 \\
\hline All & 98.0 & 2.0 & 0 & & $1.0(0.4-2.0)$ & & 1.0 \\
\hline A860T & AA & AT & TT & & & & \\
\hline $\mathrm{CAD}+\mathrm{HF}-$ & 95.9 & 4.1 & 0 & 0.12 & $2.1(0.6-5.2)$ & 0.13 & 1.0 \\
\hline $\mathrm{HF}+$ & 97.1 & 2.9 & 0 & & $1.4(0.3-4.2)$ & & 1.0 \\
\hline Newborn & 91.5 & 8.5 & 0 & & $4.3(2.5-6.7)$ & & 1.0 \\
\hline All & 94.0 & 6.0 & 0 & & $3.0(1.9-4.4)$ & & 1.0 \\
\hline
\end{tabular}

${ }^{\mathrm{a}}$ For all genotype frequencies in the three groups

b $95 \%$ confidence interval for minor allele frequency

${ }^{\mathrm{c}}$ For allele frequencies in the three groups

${ }^{\mathrm{d}}$ Exact test for deviation of genotype frequencies from the Hardy-Weinberg equilibrium 
Table 3 Frequency distribution of haplotypes comprising C34T, A99G, C143T, IVS4-6delT, G512A, C784T, and A860T AMPD1 gene sequence alterations in patients with coronary artery disease without heart failure (CAD+ $\mathrm{HF}-, n=97)$, patients with heart failure $(\mathrm{HF}+, n=104)$, and newborn controls $(n=200)$.

\begin{tabular}{|c|c|c|c|c|c|c|c|c|c|}
\hline \multicolumn{7}{|c|}{ Haplotype } & \multicolumn{3}{|l|}{ Group } \\
\hline $\mathrm{C} 34 \mathrm{~T}$ & A99G & $\mathrm{C} 143 \mathrm{~T}$ & IVS4 -6delT & G512A & $\mathrm{C} 784 \mathrm{~T}$ & A860T & $\mathrm{CAD}+\mathrm{HF}-$ & $\mathrm{HF}+$ & Newborns \\
\hline $\mathrm{C}$ & $\mathrm{A}$ & $\mathrm{C}$ & $\mathrm{T}$ & G & $\mathrm{C}$ & $\mathrm{A}$ & $149(76.8 \%)$ & $170(81.7 \%)$ & $315(78.8 \%)$ \\
\hline $\mathbf{T}$ & A & $\mathbf{T}$ & $\mathrm{T}$ & G & $\mathrm{C}$ & A & $35(18.0 \%)$ & $33(15.9 \%)$ & $62(15.5 \%)$ \\
\hline $\mathrm{C}$ & $\mathrm{A}$ & $\mathrm{C}$ & $\mathrm{T}$ & G & $\mathrm{C}$ & $\mathbf{T}$ & $4(2.1 \%)$ & $3(1.4 \%)$ & $17(4.2 \%)$ \\
\hline $\mathrm{C}$ & A & $\mathrm{C}$ & $\mathrm{T}$ & $\mathbf{A}$ & $\mathrm{C}$ & A & $4(2.1 \%)$ & $2(1.0 \%)$ & $2(0.5 \%)$ \\
\hline $\mathrm{C}$ & A & $\mathbf{T}$ & $\mathrm{T}$ & G & $\mathrm{C}$ & A & $1(0.5 \%)$ & $0(0 \%)$ & $1(0.25 \%)$ \\
\hline $\mathrm{C}$ & G & $\mathrm{C}$ & $\mathrm{T}$ & G & $\mathrm{C}$ & A & $0(0 \%)$ & $0(0 \%)$ & $2(0.5 \%)$ \\
\hline $\mathrm{C}$ & A & $\mathrm{C}$ & $\mathrm{T}$ & G & $\mathbf{T}$ & A & $1(0.5 \%)$ & $0(0 \%)$ & $0(0 \%)$ \\
\hline $\mathrm{C}$ & A & $\mathrm{C}$ & - & G & $\mathrm{C}$ & A & $0(0 \%)$ & $0(0 \%)$ & $1(0.25 \%)$ \\
\hline
\end{tabular}

Alleles different from the wild type are shown in bold

$p=0.34$, Chi-square test for all haplotype frequencies in the three groups

among wild-type (WT) homozygotes for all of the analyzed loci, 34CT heterozygotes, and 860AT heterozygotes. Due to the low number of $860 \mathrm{~T}$ carriers $(n=7)$, the $\mathrm{CAD}+\mathrm{HF}-$ and $\mathrm{HF}+$ groups were combined. Higher body mass index (BMI), prevalence of diabetes (particularly when combined with hyperglycemia), and abdominal obesity were observed in $860 \mathrm{AT}$ compared to $34 \mathrm{CT}$ heterozygotes. There was also a high proportion of women among 860AT patients. The presence of C34T mutation is associated with lower (odds ratio $[\mathrm{OR}]=0.32,95 \% \mathrm{CI}=0.13-0-81)$ and the presence of A860T with higher $(\mathrm{OR}=13.7,95 \% \mathrm{CI}=1.6-118)$ prevalence of diabetes or hyperglycemia in relation to wild-type homozygotes $(34 \mathrm{CT}<\mathrm{WT}<860 \mathrm{AT})$.

Linkage disequilibrium analysis of AMPD1 C34T and SNPs in neighboring genes

Table 5 presents the linkage disequilibrium analysis of AMPD1 C34T mutation and 1,728 single-nucleotide polymorphisms (SNPs) located in known genes at the distance of up to $1,000,000$ base pairs downstream and upstream from C34T. It is based on HapMap data for the

Table 4 Comparison of clinical data in a combined group of CAD $+\mathrm{HF}-$ and HF+ patients stratified according to the AMPD1 genotype

\begin{tabular}{|c|c|c|c|c|c|c|}
\hline \multirow[t]{2}{*}{$A M P D 1$ genotype } & \multirow[t]{2}{*}{ WT $(n=128)$} & \multirow[t]{2}{*}{$34 \mathrm{CT}(n=49)$} & \multirow[t]{2}{*}{$860 \mathrm{AT}(n=7)$} & \multicolumn{3}{|c|}{ Statistical significance $^{\mathrm{a}}$} \\
\hline & & & & $\begin{array}{l}34 \mathrm{CT} \text { vs. } \\
\text { WT }\end{array}$ & $\begin{array}{l}860 \text { AT vs. } \\
\text { WT }\end{array}$ & $\begin{array}{l}860 \mathrm{AT} \text { vs. } \\
34 \mathrm{CT}\end{array}$ \\
\hline Age (years) & $59.3 \pm 8.3$ & $57.8 \pm 9.7$ & $59.1 \pm 8.7$ & 0.25 & 0.88 & 0.66 \\
\hline Female gender & $26(20 \%)$ & $9(18 \%)$ & $4(57 \%)$ & 0.84 & 0.043 & 0.043 \\
\hline BMI $\left(\mathrm{kg} / \mathrm{m}^{2}\right)$ & $28.2 \pm 4.3$ & $27.1 \pm 3.3$ & $32.7 \pm 7.7$ & 0.21 & 0.087 & 0.046 \\
\hline Obesity (BMI $\geq 30 \mathrm{~kg} / \mathrm{m}^{2}$ ) & $43(34 \%)$ & $11(22 \%)$ & $4(57 \%)$ & 0.20 & 0.24 & 0.074 \\
\hline Waist $(\mathrm{cm})$ & $97.0 \pm 11.3$ & $93.8 \pm 11.2$ & $104.3 \pm 16.0$ & 0.067 & 0.18 & 0.072 \\
\hline Waist $\geq 102 \mathrm{~cm}$ (males) or $\geq 88 \mathrm{~cm}$ (females) $^{\mathrm{b}}$ & $51(40 \%)$ & $14(29 \%)$ & $6(86 \%)$ & 0.22 & 0.041 & 0.0064 \\
\hline Diabetes type 2 & $28(22 \%)$ & $4(8 \%)$ & $4(57 \%)$ & 0.048 & 0.054 & 0.0055 \\
\hline $\mathrm{FPG} \geq 126 \mathrm{mg} / \mathrm{dL}$ & $32(25 \%)$ & $6(12 \%)$ & $2(29 \%)$ & 0.069 & 1.0 & 0.26 \\
\hline Diabetes or FPG $\geq 126 \mathrm{mg} / \mathrm{dL}$ & $39(30 \%)$ & $6(12 \%)$ & $6(86 \%)$ & 0.012 & 0.0056 & 0.00018 \\
\hline
\end{tabular}

FPG - fasting plasma glucose; WT - wild-type for all analyzed loci

${ }^{a}$ Fisher's exact test for qualitative variables and the Mann-Whitney test for quantitative variables; significant differences are shown in bold

${ }^{\mathrm{b}}$ Criterion of abdominal obesity according to NCEP ATP III (2001)

Data are given as mean \pm standard deviation (SD) for quantitative variables or number (percentage) of patients with the indicated feature for qualitative variables 
Table 5 Linkage analysis of $A M P D 1$ C34T polymorphism (position 115037580 on chromosome 1) and other polymorphisms (SNPs) located in known genes at the distance of up to $1,000,000$ base pairs.
LOD score and $r^{2}$ values for the most strongly linked polymorphism in each gene are shown

\begin{tabular}{|c|c|c|c|c|c|}
\hline Gene & Chromosome 1 location & Number of SNPs & Number $(\%)$ of SNPs with LOD score $>2$ & Maximal LOD score & Maximal $r^{2}$ \\
\hline PHTF1 & $114041360-114102879$ & 17 & $0(0 \%)$ & 0.57 & 0.019 \\
\hline RSBN1 & $114105977-114156593$ & 27 & $0(0 \%)$ & 0.89 & 0.027 \\
\hline PTPN22 & $114157960-114215857$ & 32 & $0(0 \%)$ & 0.89 & 0.037 \\
\hline$B C L 2 L 15$ & $114220959-114231692$ & 9 & $0(0 \%)$ & 0.47 & 0.016 \\
\hline$A P 4 B 1$ & $114239201-114249215$ & 8 & $0(0 \%)$ & 0.37 & 0.019 \\
\hline DCLREIB & $114249561-114258217$ & 6 & $0(0 \%)$ & 0.22 & 0.008 \\
\hline HIPK1 & $114273519-114321945$ & 24 & $0(0 \%)$ & 0.34 & 0.017 \\
\hline OLFML3 & $114323553-114326398$ & 3 & $0(0 \%)$ & 0.42 & 0.021 \\
\hline LOC100132906 & $114345578-114347488$ & 1 & $0(0 \%)$ & 0 & 0 \\
\hline SYT6 & 114433437 - 114497995 & 121 & $0(0 \%)$ & 1.03 & 0.063 \\
\hline$M R P 63 P 1$ & $114623147-114623431$ & 0 & - & - & - \\
\hline TRIM33 & $114736922-114855304$ & 41 & $1(2 \%)$ & 2.55 & 0.149 \\
\hline LOC643586 & 114864161 - 114881992 & 10 & $2(20 \%)$ & 8.65 & 0.468 \\
\hline$B C A S 2$ & 114911701 - 114925788 & 6 & $3(50 \%)$ & 11.99 & 0.665 \\
\hline DENND2C & $114928719-115014255$ & 42 & $19(45 \%)$ & 11.99 & 0.665 \\
\hline$A M P D 1$ & $115017245-115039699$ & 12 & $7(58 \%)$ & 11.99 & 0.665 \\
\hline NRAS & $115051108-115061038$ & 3 & $2(67 \%)$ & 8.93 & 0.332 \\
\hline CSDE1 & $115061060-115102147$ & 25 & $7(28 \%)$ & 13.07 & 0.585 \\
\hline SIKE & $115113623-115124831$ & 3 & $0(0 \%)$ & 1.49 & 0.049 \\
\hline NR1H5P & $115178857-115199038$ & 17 & $5(29 \%)$ & 6.72 & 0.223 \\
\hline$S Y C P 1$ & $115198978-115339514$ & 77 & $49(64 \%)$ & 9.08 & 0.45 \\
\hline$T S H B$ & $115373938-115378464$ & 6 & $4(67 \%)$ & 3.87 & 0.157 \\
\hline TSPAN2 & $115392155-115433638$ & 79 & $43(54 \%)$ & 7.33 & 0.343 \\
\hline$N G F$ & $115630060-115682380$ & 100 & $0(0 \%)$ & 1.13 & 0.056 \\
\hline LOC100132332 & $115908526-115909576$ & 0 & - & - & - \\
\hline VANGL1 & $115986097-116042368$ & 91 & $0(0 \%)$ & 1.18 & 0.051 \\
\hline
\end{tabular}

PHTF1 - putative homeodomain transcription factor 1 ; RSBN1 - round spermatid basic protein 1; PTPN22 - protein tyrosine phosphatase, nonreceptor type 22 (lymphoid); $B C L 2 L 15$ - BCL2-like 15; AP4B1 - adaptor-related protein complex 4, beta 1 subunit; DCLRE1B - DNA cross-link repair 1B (PSO2 homolog); HIPK1 - homeodomain interacting protein kinase 1; OLFML3 - olfactomedin-like 3; LOC100132906 - similar to mCG23455, pseudogene; SYT6 - synaptotagmin VI; MRP63P1 - mitochondrial ribosomal protein 63 pseudogene 1; TRIM33 - tripartite motifcontaining 33; LOC643586 - similar to pyruvate kinase, muscle, pseudogene; BCAS2 - breast carcinoma amplified sequence 2; DENND2C DENN/MADD domain containing 2C; $A M P D 1$ - adenosine monophosphate deaminase 1;NRAS - neuroblastoma RAS viral (v-ras) oncogene homolog; CSDE1 - cold shock domain containing E1; SIKE - suppressor of IKK epsilon; NR1H5P - nuclear receptor subfamily 1, group H, member 5 pseudogene; SYCP1 - synaptonemal complex protein 1; TSHB - thyroid stimulating hormone, beta; TSPAN2 - tetraspanin 2; NGF nerve growth factor (beta polypeptide); LOC100132332 - similar to CCR4-NOT transcription complex, subunit 7, pseudogene; VANGL1 - vanglike 1 (van gogh, Drosophila)

CEU population containing genotypes of 60 unrelated subjects of European descent, including 12 (20\%) 34CT heterozygotes and two (3.3\%) 34TT homozygotes. No other $A M P D 1$ sequence alterations described in the current paper were present in the HapMap database.

A region with strong linkage ranges as far as $400,000 \mathrm{bp}$ upstream of the AMPD1 gene, up to the TSPAN2 gene. After the exclusion of pseudogenes, nine genes (TRIM33, BCAS2, DENND2C, NRAS, CSDE1, SIKE, SYCP1, TSHB, TSPAN2) contain polymorphisms linked with the AMPD1 $\mathrm{C} 34 \mathrm{~T}$ mutation. It cannot be excluded that one of these polymorphisms is directly responsible for the observed associations with obesity and diabetes, while AMPD1 mutations are just genetic markers without functional connection to metabolic syndrome.

\section{Discussion}

In the current study, we analyzed selected exons of the AMPD1 gene (where non-synonymous mutations leading to loss of muscle AMP deaminase activity had been described 
previously) in patients with cardiovascular diseases and in newborn controls. We chose exon 2 with the well-known C34T (Gln12Stop) mutation, exon 3 with equally frequent C143T (Pro48Leu) substitution, exon 5 with G468T (Gln156His) mutation found in the German population (Gross et al. 2002), and exon 7 with A860T (Lys287Ile) (Toyama et al. 2004) described in Europeans. The presence of the same genotype at loci 34 (RFLP method) and 143 (DHPLC) was an additional proof of correct genotyping: when the results were discordant, direct sequencing was performed to confirm the rare combination of genotypes at both loci.

Our results have shown that, in the Polish population, similarly to other Europeans, the most frequent alterations of the AMPD1 coding sequence are $\mathrm{C} 34 \mathrm{~T}$ and $\mathrm{C} 143 \mathrm{~T}$, which are strongly linked with each other. The most numerous group of Europeans genotyped for the AMPD1 C34T mutation so far is a cohort of 2,707 healthy British subjects (Webb et al. 2006) with the frequency of $34 \mathrm{~T}$ allele equal to $13 \%$, which is at the lower limit of confidence intervals for our groups (Table 2). The 34T frequency in a group of 721 healthy subjects from south-western Germany was $14.5 \%$ (Frank et al. 2008), while in 175 healthy Swedes, it was $13.7 \%$ (Norman et al. 1998). It seems that the $34 \mathrm{~T}$ allele frequency is similar in various European populations, including patients and newborns examined in the current study.

According to previous reports, A860T mutation is present in 3\% alleles of healthy subjects of European descent (Toyama et al. 2004). The $860 \mathrm{~T}$ allele frequency was $2.6 \%$ in healthy Americans of European origin (Isackson et al. 2005) and 2.8\% in the healthy German population (Hanisch et al. 2008). These values are in agreement with results of the current study (Table 2). Four other detected sequence alterations (A99G in exon 3, IVS46delT in intron 4, G512A in exon 5, C784T in exon 7) have not been described previously.

We have not found any case of G468T mutation. This variant is probably very rare and limited to Germany, since it has not been detected in 230 subjects (healthy or with myopathy) from various populations (Toyama et al. 2004) and in 704 healthy Swedes (Fischer et al. 2007). Similarly, we have not found del404T mutation in exon 5, which was detected in two of 879 Swedes (Norman et al. 1998; Fischer et al. 2007).

The genotype combination $34 \mathrm{TT}+143 \mathrm{CT}$ was detected in $0.5 \%$ of subjects, which is similar to the $0.7 \%$ frequency found in Americans of European origin (Isackson et al. 2005). Other previously described rare combinations $(34 \mathrm{CT}+143 \mathrm{CC}$ and 34CT+143TT) (Fishbein et al. 1997) were not found in our population.

Functional impact of detected $A M P D 1$ sequence alterations

Since our study did not involve the assessment of muscle AMP deaminase activity, we present the analysis of the possible impact of the detected alterations on enzyme function based on the previous reports and comparative genomics. The C34T mutation in exon 2 (Gln12Stop) definitely leads to the termination of translation and results in the lack of immunoreactive protein (Morisaki et al. 1992) and enzyme activity (about $1 \%$ of normal) in homozygotes (Norman et al. 1998). Alternative splicing excluding exon 2 may partly explain the residual AMPD activity and hypothetically protect from the metabolic consequences of the defect (Morisaki et al. 1993), but this theory needs to be proven.

The C143T transition (Pro48Leu) in most cases accompanies $\mathrm{C} 34 \mathrm{~T}$ and has no functional meaning, since translation terminates at codon 12. However, it could be introduced into the protein if exon 2 was excluded due to alternative splicing. A study analyzing the expression of cDNA with $143 \mathrm{~T}$ and $34 \mathrm{C}$ in Escherichia coli did not show altered enzyme activity (Morisaki et al. 1992), but its stability and affinity were not analyzed, and the influence on human muscle AMPD activity is unknown. Proline is exceptionally conservative and present in all analyzed vertebrates at the position corresponding to Pro48 in human AMPD1, together with adjacent amino acids, forming the sequence Cys-Pro-Ile. This sequence is also present in the human AMPD3 protein and all of its orthologs in vertebrates, while in human AMPD2, the sequence is SerPro-Ile. Proline is conservative also in AMPD proteins of nonvertebrates (Tyr-Pro-Ile sequence in Caenorhabditis elegans), and even in plants (Arabidopsis thaliana) (Han et al. 2006). The adjacent AMPD1 region encompassing AA 51-60 is a putative zinc-binding site (Martini et al. 2007) and has an $\alpha$ helix structure (Mangani et al. 2007). Proline-induced break of the $\alpha$-helix may be important for proper spatial conformation of the $\mathrm{Zn}^{2+}$-binding domain. The remarkable evolutionary conservativeness of Pro48 needs further investigation, which could elucidate the effects of C143T substitution in the case of alternative splicing excluding exon 2.

A860T transversion (Lys287Ile) affects the AMPD1 region responsible for myosin binding. Lysine is totally conservative in the corresponding position of AMPD1, AMPD2, and AMPD3 proteins in vertebrates and in most non-vertebrates and plants. In some protozoa, lysine is substituted by arginine, a basic amino acid with similar properties. The recombined mutated protein has decreased both the activity and affinity for AMP by half in relation to wild-type enzyme (Toyama et al. 2004). Two reported cases confirm impaired function of the mutated enzyme in vivo. The muscle AMPD activity in a subject with myopathy symptoms who turned out to be a compound heterozygote with IVS2-(4-7)delCTTT and A860T mutations was 20-25\% of normal (Isackson et al. 2005). Another compound heterozygote with $\mathrm{C} 34 \mathrm{~T}$ and $\mathrm{A} 860 \mathrm{~T}$ mutations had the activity equal to about $40 \%$ of common $34 \mathrm{CT}$ heterozygotes (Hanisch et al. 2008). It seems that the activity of enzyme 
encoded by $860 \mathrm{~T}$ allele is $40-50 \%$ in relation to the enzyme encoded by wild-type allele.

G512A transition (Gly171Asp) is the most frequent $A M P D 1$ alteration not described previously. Gly171 is fully conservative in all of analyzed AMPD1 proteins in mammals, chicken, frog, and fish, but it is substituted by asparagine in lizard. Mammal AMPD2 contains alanine and AMPD3 may contain alanine, glycine, or threonine. AMPDs in non-vertebrates contain such different amino acids as leucine, proline, and glutamate. These data suggest relatively low conservation and, possibly, the lack of functional impact of Gly171Asp alteration.

C784T (Arg262Trp) changes arginine residue, which is very conservative in AMPD1, AMPD2, and AMPD3 proteins of all 26 analyzed vertebrates, as well as in AMPD of insects, nematodes, and most fungi and plants (Arabidopsis thaliana). In some fungi and protozoa, arginine is substituted by similar basic lysine or histidine. Only a few protozoa contain other amino acids (glutamine, tyrosine, aspartate, glutamate). In FAC1 protein with AMPD activity in A. thaliana, the corresponding Arg (position 350 in the Swiss-Prot O80452 sequence) is located in an $\alpha$-helix structure in the middle of the His-Arg-Arg sequence, which forms a positively charged flat surface (Han et al. 2006). These facts suggest the high probability of functional impact of the C784T substitution.

The intron 4 region with IVS4-6delT alteration (cttttttttttggcagGTT) contains a typical splice acceptor sequence: pyrimidine-rich tract and "ag" at the intron-exon boundary. The deletion shortens the tract from 12 to 11 thymines. The chimpanzee AMPD1 intron 4-exon 5 boundary is identical to the human sequence, but for the presence of $11 \mathrm{~T}$ instead of $12 \mathrm{~T}$, just like in the human IVS4-6delT variant. In other primates, the pyrimidine-rich tract may be as short as $7 \mathrm{bp}$. These facts are evidence against the functional role of the deletion.

Synonymous A99G (Gly33Gly) transition in exon 3 deletes one of five ESE motifs specific for the SF2/ASF protein (AGGAGGT) with relatively low score (2.43) and creates the ESS motif (AGGGGG), but it does not affect the ESE motifs specific for other SR proteins (SC35, SRp40, SRp55). Adenine is present in eight of ten mammals as coding nucleotide 99, while guanine is found in two (rabbit and tenrec). It suggests that the A99G variant lacks functional significance.

\section{$A M P D 1$ and cardiovascular diseases}

Similarly to all earlier studies, we did not find significant differences in the $\mathrm{C} 34 \mathrm{~T}$ polymorphism genotype distributions in the study groups $(\mathrm{CAD}+\mathrm{HF}-$ and $\mathrm{HF}+$ ) and in a random control group consisting of consecutive newborns from the same population as the study groups (Table 2). The T34 allele does not prevent the development of either CAD or HF, though it seems to protect from the known risk factors of CAD, such as abdominal obesity and diabetes (Safranow et al. 2009). We did not find significant differences between groups for the other detected sequence alterations, but the 860T allele was less frequent in a combined group of patients than in newborns. It could be interpreted as a protective effect of the $\mathrm{T}$ allele against cardiovascular diseases, but such a hypothesis should be treated with caution due to the low number of $860 \mathrm{~T}$ carriers and moderate statistical significance.

\section{$A M P D 1$ and diabetes}

It was reported that variation in the AMPD1 gene is associated with insulin clearance and may participate in the syndromes of insulin resistance (Goodarzi et al. 2005). In the previous paper (Safranow et al. 2009), we demonstrated that the carriage of T34 mutated allele in CAD patients without $\mathrm{HF}$ is associated with a lower prevalence of two features of metabolic syndrome, diabetes and obesity, while in patients with HF, it is associated with lower fasting glucose. Hypothetically, the activity of AMPD can influence the activity of AMP-activated protein kinase (AMPK), which controls cellular energy balance (e.g., by stimulating cellular glucose uptake), affecting the development of type 2 diabetes in many ways (Gerbitz et al. 1996). In this study, we compared the influence of C34T and A860T mutations on obesity and diabetes in a combined group of patients with and without HF. Surprisingly, their effect proved opposite: 34CT heterozygotes had a significantly lower frequency of diabetes than wild-type homozygotes, but in 860AT heterozygotes, the prevalence of diabetes and obesity was higher than in WT and 34CT patients. These differences were particularly significant when the presence of diabetes or fasting plasma glucose $\geq 126 \mathrm{mg} / \mathrm{dL}$ was analyzed (12\% vs. $30 \%$ vs. $86 \%$ prevalence for $34 \mathrm{CT}$, WT, and $860 \mathrm{AT}$, respectively). The difference in metabolic effects of the two mutations might be explained by the different ways of enzyme protein modification: termination of translation by $\mathrm{C} 34 \mathrm{~T}$ and reduction of the activity by $40-50 \%$ in the case of A860T. Alternatively, the explanation might be the linkage disequilibrium of $A M P D 1$ mutations with functional variants in neighboring genes.

\section{Linkage analysis of AMPD1 C34T polymorphism}

Since the AMPD1 gene is expressed at a high level only in skeletal muscles, the mechanisms of genotype-phenotype association between its mutations and clinical features of patients with cardiovascular diseases remain unclear. Therefore, a possibility of linkage with unknown sequence alteration within another gene should be taken into account. The nine genes containing polymorphisms linked with AMPD1 C34T mutation (Table 5) play various roles, and in 
most cases, their function is poorly understood. TRIM33 encodes transcription corepressor. BCAS2 is expressed in breast tumors, interacting with estrogen receptors. DENND2C encodes protein with the DENN domain and unknown function. Other proteins containing the DENN domain participate in mitogen-activated protein kinases (MAPK) pathways. Membrane protein encoded by NRAS oncogene plays a part in MAPK pathways and in signaling through insulin receptor. Unr protein encoded by $C S D E 1$ gene is an RNA chaperon, SIKE participates in the inhibition of interferon secretion during viral infection, and $S Y C P 1$ codes for synaptonemal transverse filament protein. TSPAN2 encodes a membrane protein classified as one of the tetraspanins, which participate in the transduction of signals controlling cell development, activation, growth, and movement. TSHB encoding the beta subunit of thyrotropic hormone (TSH) is particularly interesting, since its mutations lead to congenital secondary hypothyroidism (Karges et al. 2004), while both hypo- and hyperthyroidism are recognized risk factors for cardiovascular diseases. We have not found any reports analyzing the association between polymorphisms of the above-mentioned genes and cardiovascular diseases.

\section{Conclusions}

The most frequent mutation of the AMPD1 gene in the Polish population is the $\mathrm{C} 34 \mathrm{~T}$ substitution, associated with reduced prevalence of diabetes and obesity in patients with coronary artery disease (CAD) or heart failure (HF). The A860T mutation seems to exert metabolic effects differing from C34T and should always be accounted for in studies of the AMPD1 genotype. The potential association of this mutation with reduced risk of cardiovascular disease, as well as with increased prevalence of obesity and diabetes, merits further study in a larger population of patients. Due to the strong linkage of $A M P D 1$ mutations with sequence alterations in the TRIM33, BCAS2, DENND2C, NRAS, CSDE1, SIKE, SYCP1, $T S H B$, and TSPAN2 genes, it seems prudent to analyze the effect of these alterations on the associations between clinical and metabolic parameters and the AMPD1 genotype.

Acknowledgments This study was supported by grant 2 P05B 079 26 from the Polish Committee for Scientific Research.

Open Access This article is distributed under the terms of the Creative Commons Attribution Noncommercial License which permits any noncommercial use, distribution, and reproduction in any medium, provided the original author(s) and source are credited.

\section{References}

Agresti A (1992) A survey of exact inference for contingency tables. Stat Sci 7:131-177
Altschul SF, Madden TL, Schäffer AA, Zhang J, Zhang Z, Miller W, Lipman DJ (1997) Gapped BLAST and PSI-BLAST: a new generation of protein database search programs. Nucleic Acids Res 25:3389-3402

Anderson JL, Habashi J, Carlquist JF, Muhlestein JB, Horne BD, Bair TL, Pearson RR, Hart N (2000) A common variant of the $A M P D 1$ gene predicts improved cardiovascular survival in patients with coronary artery disease. J Am Coll Cardiol 36:1248-1252

Andreassi MG, Botto N, Laghi-Pasini F, Manfredi S, Ghelarducci B, Farneti A, Solinas M, Biagini A, Picano E (2005) AMPD1 (C34T) polymorphism and clinical outcomes in patients undergoing myocardial revascularization. Int J Cardiol 101:191195

Barrett JC, Fry B, Maller J, Daly MJ (2005) Haploview: analysis and visualization of LD and haplotype maps. Bioinformatics 21:263265

Cartegni L, Wang J, Zhu Z, Zhang MQ, Krainer AR (2003) ESEfinder: a web resource to identify exonic splicing enhancers. Nucleic Acids Res 31:3568-3571

Clopper CJ, Pearson ES (1934) The use of confidence or fiducial limits illustrated in the case of the binomial. Biometrika 26:404413

Collins RP, Palmer BR, Pilbrow AP, Frampton CM, Troughton RW, Yandle TG, Skelton L, Richards AM, Cameron VA (2006) Evaluation of AMPD1 C34T genotype as a predictor of mortality in heart failure and post-myocardial infarction patients. Am Heart J 152:312-320

de Groote P, Lamblin N, Helbecque N, Mouquet F, Hermant X, Amouyel P, Dallongeville J, Bauters C (2006) The impact of the AMPD1 gene polymorphism on exercise capacity, other prognostic parameters, and survival in patients with stable congestive heart failure: a study in 686 consecutive patients. Am Heart J 152:736-741

Expert Panel on Detection, Evaluation, and Treatment of High Blood Cholesterol in Adults (2001) Executive Summary of The Third Report of The National Cholesterol Education Program (NCEP) Expert Panel on Detection, Evaluation, and Treatment of High Blood Cholesterol in Adults (Adult Treatment Panel III). JAMA 285:2486-2497

Fischer S, Drenckhahn C, Wolf C, Eschrich K, Kellermann S, Froster UG, Schober R (2005) Clinical significance and neuropathology of primary MADD in C34-T and G468-T mutations of the AMPD1 gene. Clin Neuropathol 24:77-85

Fischer H, Esbjörnsson M, Sabina RL, Strömberg A, Peyrard-Janvid M, Norman B (2007) AMP deaminase deficiency is associated with lower sprint cycling performance in healthy subjects. J Appl Physiol 103:315-322

Fishbein WN, Davis JI, Foellmer JW, Nieves S, Merezhinskaya N (1997) A competitive allele-specific oligomers polymerase chain reaction assay for the cis double mutation in AMPD1 that is the major cause of myo-adenylate deaminase deficiency. Mol Diagn 2:121-128

Frank B, Burwinkel B, Bermejo JL, Försti A, Hemminki K, Houlston R, Mangold E, Rahner N, Friedl W, Friedrichs N, Buettner R, Engel C, Loeffler M, Holinski-Feder E, Morak M, Keller G, Schackert HK, Krüger S, Goecke T, Moeslein G, Kloor M, Gebert J, Kunstmann E, Schulmann K, Rüschoff J, Propping P; German HNPCC Consortium (2008) Ten recently identified associations between nsSNPs and colorectal cancer could not be replicated in German families. Cancer Lett 271:153-157

Gastmann A, Sigusch HH, Henke A, Reinhardt D, Surber R, Gastmann O, Figulla HR (2004) Role of adenosine monophosphate deaminase-1 gene polymorphism in patients with congestive heart failure (influence on tumor necrosis factor-alpha level and outcome). Am J Cardiol 93:1260-1264 
Gerbitz KD, Gempel K, Brdiczka D (1996) Mitochondria and diabetes. Genetic, biochemical, and clinical implications of the cellular energy circuit. Diabetes 45:113-126

Goodarzi MO, Taylor KD, Guo X, Quiñones MJ, Cui J, Li X, Hang T, Yang H, Holmes E, Hsueh WA, Olefsky J, Rotter JI (2005) Variation in the gene for muscle-specific AMP deaminase is associated with insulin clearance, a highly heritable trait. Diabetes 54:1222-1227

Gross M (1997) Clinical heterogeneity and molecular mechanisms in inborn muscle AMP deaminase deficiency. J Inherit Metab Dis 20:186-192

Gross M, Rötzer E, Kölle P, Mortier W, Reichmann H, Goebel HH, Lochmüller H, Pongratz D, Mahnke-Zizelman DK, Sabina RL (2002) A G468-T AMPD1 mutant allele contributes to the high incidence of myoadenylate deaminase deficiency in the Caucasian population. Neuromuscul Disord 12:558-565

Guo SW, Thompson EA (1992) Performing the exact test of HardyWeinberg proportion for multiple alleles. Biometrics 48:361-372

Han BW, Bingman CA, Mahnke DK, Bannen RM, Bednarek SY, Sabina RL, Phillips GN Jr (2006) Membrane association, mechanism of action, and structure of Arabidopsis embryonic factor 1 (FAC1). J Biol Chem 281:14939-14947

Hanisch F, Joshi P, Zierz S (2008) AMP deaminase deficiency in skeletal muscle is unlikely to be of clinical relevance. J Neurol 255:318-322

International HapMap Consortium (2007) A second generation human haplotype map of over 3.1 million SNPs. Nature 449:851-861

Isackson PJ, Bujnicki H, Harding CO, Vladutiu GD (2005) Myoadenylate deaminase deficiency caused by alternative splicing due to a novel intronic mutation in the AMPD1 gene. Mol Genet Metab 86:250 256

Jones AC, Austin J, Hansen N, Hoogendoorn B, Oefner PJ, Cheadle JP, O'Donovan MC (1999) Optimal temperature selection for mutation detection by denaturing HPLC and comparison to single-stranded conformation polymorphism and heteroduplex analysis. Clin Chem 45:1133-1140

Karges B, LeHeup B, Schoenle E, Castro-Correia C, Fontoura M, Pfäffle R, Andler W, Debatin KM, Karges W (2004) Compound heterozygous and homozygous mutations of the TSHbeta gene as a cause of congenital central hypothyroidism in Europe. Horm Res 62:149-155

Kolek MJ, Carlquist JF, Thaneemit-Chen S, Lazzeroni LC, Whiting BM, Horne BD, Muhlestein JB, Lavori P, Anderson JL (2005) The role of a common adenosine monophosphate deaminase (AMPD)-1 polymorphism in outcomes of ischemic and nonischemic heart failure. J Card Fail 11:677-683

Kurzawski G, Safranow K, Suchy J, Chlubek D, Scott RJ, Lubiński J (2002) Mutation analysis of MLH1 and MSH2 genes performed by denaturing high-performance liquid chromatography. J Biochem Biophys Methods 51:89-100

Loh E, Rebbeck TR, Mahoney PD, DeNofrio D, Swain JL, Holmes EW (1999) Common variant in AMPD1 gene predicts improved clinical outcome in patients with heart failure. Circulation 99:1422-1425

Mangani S, Benvenuti M, Moir AJ, Ranieri-Raggi M, Martini D, Sabbatini AR, Raggi A (2007) Characterization of the metallocenter of rabbit skeletal muscle AMP deaminase. Evidence for a dinuclear zinc site. Biochim Biophys Acta 1774:312-322

Martini D, Ranieri-Raggi M, Sabbatini AR, Moir AJ, Polizzi E, Mangani S, Raggi A (2007) Characterization of the metallocenter of rabbit skeletal muscle AMP deaminase. A new model for substrate interactions at a dinuclear cocatalytic $\mathrm{Zn}$ site. Biochim Biophys Acta 1774:1508-1518

Morisaki T, Sabina RL, Holmes EW (1990) Adenylate deaminase. A multigene family in humans and rats. J Biol Chem 265:11482-11486

Morisaki T, Gross M, Morisaki H, Pongratz D, Zöllner N, Holmes EW (1992) Molecular basis of AMP deaminase deficiency in skeletal muscle. Proc Natl Acad Sci USA 89:6457-6461

Morisaki H, Morisaki T, Newby LK, Holmes EW (1993) Alternative splicing: a mechanism for phenotypic rescue of a common inherited defect. J Clin Invest 91:2275-2280

Morisaki H, Higuchi I, Abe M, Osame M, Morisaki T (2000) First missense mutations (R388W and R425H) of AMPD1 accompanied with myopathy found in a Japanese patient. Hum Mutat $16: 467-472$

Norman B, Mahnke-Zizelman DK, Vallis A, Sabina RL (1998) Genetic and other determinants of AMP deaminase activity in healthy adult skeletal muscle. J Appl Physiol 85:1273-1278

Sabina RL, Swain JL, Patten BM, Ashizawa T, O'Brien WE, Holmes EW (1980) Disruption of the purine nucleotide cycle. A potential explanation for muscle dysfunction in myoadenylate deaminase deficiency. J Clin Invest 66:1419-1423

Sabina RL, Morisaki T, Clarke P, Eddy R, Shows TB, Morton CC, Holmes EW (1990) Characterization of the human and rat myoadenylate deaminase genes. J Biol Chem 265:9423-9433

Safranow K, Czyzycka E, Binczak-Kuleta A, Rzeuski R, Skowronek J, Wojtarowicz A, Jakubowska K, Olszewska M, Loniewska B, Kaliszczak R, Kornacewicz-Jach Z, Ciechanowicz A, Chlubek D (2009) Association of C34T AMPD1 gene polymorphism with features of metabolic syndrome in patients with coronary artery disease or heart failure. Scand J Clin Lab Invest 69:102-112

Toyama K, Morisaki H, Kitamura Y, Gross M, Tamura T, Nakahori Y, Vance JM, Speer M, Kamatani N, Morisaki T (2004) Haplotype analysis of human AMPD1 gene: origin of common mutant allele. J Med Genet 41:e74

Wang Z, Rolish ME, Yeo G, Tung V, Mawson M, Burge CB (2004) Systematic identification and analysis of exonic splicing silencers. Cell 119:831-845

Webb EL, Rudd MF, Sellick GS, El Galta R, Bethke L, Wood W, Fletcher O, Penegar S, Withey L, Qureshi M, Johnson N, Tomlinson I, Gray R, Peto J, Houlston RS (2006) Search for low penetrance alleles for colorectal cancer through a scan of 1467 non-synonymous SNPs in 2575 cases and 2707 controls with validation by kin-cohort analysis of 14704 first-degree relatives. Hum Mol Genet 15:3263-3271

Yazaki Y, Muhlestein JB, Carlquist JF, Bair TL, Horne BD, Renlund DG, Anderson JL (2004) A common variant of the AMPD1 gene predicts improved survival in patients with ischemic left ventricular dysfunction. J Card Fail 10:316-320 